\title{
Perception of Nurses' Work in Psychiatric Clinic
}

\author{
Dr. Kratika Daniel ${ }^{1^{*} \odot \text { | Dr Vivek Daniel }}{ }^{2}$ ()
}

${ }^{1}$ Associate professor, Faculty of Pharmacy, Mandsaur University, Mandsaur, M.P. India

${ }^{2}$ Associate professor, Department of Pharmacy, JEES, Nandurbar, Maharashtra, India2Associate

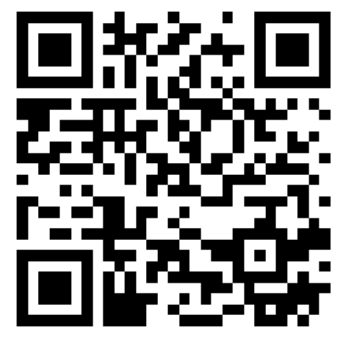

\begin{abstract}
Purpose: This study aims to determine the siege and related factors of nurses working in psychiatric clinics.

Method: This study was conducted as a related description design. The sample of the study consisted of 204 nurses working in psychiatric clinics. The data was collected using questionnaires generated by researchers from literature and workplace psychological abuse scales. Descriptive statistics (frequency and percentage) and chi-square independence test are used to determine whether there is a significant relationship between variables.

Results: The conditions for more frequent siege behaviors are that nurses have graduate education, work at night, are dissatisfied with work methods and institutions, have been besieged before, and have an understanding of the number of legal persons and consulting services related to Go.

Conclusion: The nursing service management department of the hospital should effectively organize the types of employment and develop strategies that can improve nurse satisfaction. It is believed that raising nurses' awareness of siege will effectively reduce psychological violence in high-risk wards.

Keywords: Siege, workplace violence, mental health, psychiatry, psychiatric nurse, mental health nurse

Copyright : (C) 2020 The Authors. Published by Medical Editor and Educational Research Publishers Ltd. This is an open access article under the CC BY-NC-ND license (https://creativecommons.org/licenses/by-nc-nd/4.0/).
\end{abstract}

\section{1 | INTRODUCTION}

$\mathrm{M}$ obbing is a nonphysical form of workplace violence (WBI 2014), a concept which has different meanings such as de- terring and pressure, psychological violence, bullying, rudeness, hostile attitude, psychological terrorism in workplace (Leymann 1996) and it threatens employee safety and productivity in the workplace (Johnston et al. 2009), reduces business performance 
(Y1ldırım 2009), work and workplace satisfaction and involves the intention of withdrawal from work (Wachs 2009, Davenport et al. 2003), causes psychological and physical traumas on person, results in many negativities for the employee and the organization. Mobbing is a situation that creates conflict through showing annoying behavior that targets a certain person for a long time and systematically (at least once a week and lasts for at least 6 months). At the same time, it is a direct or indirect psychological attack expressed through abusive conduct, threatening, humiliating, exclusion and intimidation (Zapf 1999, Davenport et al. 2003, WBI 2014). Leymann, who explained the concept of mobbing for the first time, defines it as 'psychological violence or psychological terrorism towards one person or more that leaves people helpless and vulnerable through systematic hostile and unethical communication in business life' (Leymann 1996, Karsavuran 2014). Once mobbing/psychological violence in workplace is categorized into subtitles; it is actualized through systematic behaviors to targeted person as threat/intimidation, blocking communication with others and isolation from social relations, humiliation/underestimation, direct physical/sexual violence towards occupational skills. Mobbing has significant negative effects on work satisfaction, self-esteem and burnout experience as well as having psychological, physical and behavioral effects (Bradbury and Hutchinson 2015, Nielsen and Einarsen 2012, Iglesias and Vallejo 2012, Giorgi et al. 2015). Institutions where there is mobbing, not only the victim but also the witnesses are affected. These people are both sorry for the real victim and concerned about being victimized. Organizations also pay a heavy cost because of mobbing (Johnston et al. 2009, Iglesias and Vallejo 2012, Khoshknab et al. 2015, Y1ldirım and Yildırım 2007, Karsavuran 2014). Mobbing, which is a state of psychological violence, not only affects

Supplementary information The online version of this article $(10.52845 / \mathrm{CMI} / 2020 \mathrm{v} 1 \mathrm{ila} 5)$ contains supplementary material, which is available to authorized users.

\section{Corresponding Author: Dr. Kratika Daniel} Dr. Kratika Daniel

Email:kratika.daniel@meu.edu.in employees and institutions in the health sector but also affects the quality of patient care and patient safety, leads to medical errors, creates interdisciplinary conflict and stress in healthcare professionals (Hamilton 2007, Johnston 2009). For this reason, mobbing in the workplace experienced by nurses who play a critical role in patient care has a particular importance such as decline in patient care quality.

The main source of mobbing formation is expressed as personal traits (personal ambition, envy, jealousy, gender, marital status etc.) (Adams 1992). Heavy workload and difficult working conditions, unresolved conflicts, lack of sense of trust and justice, ineligible and oppressive executive trigger mobbing behaviors in situations (Johnston et al. 2009; Park et al. 2015). Organization climate from organizational factors is another factor related to mobbing. When there are negative behaviors in the organizations, which means the organizational climate is negative, the employee feels oneself as a mobbing victim and this causes health problems and burnout experience for the employees (Giorgi ve ark. 2015). The organizational culture which tolerates violence in the workplace is another important factor that creates mobbing. In the organizations in which the lines for the mobbing behavior are not drawn, the climate changes and these behaviors are unintentionally supported. Nursing is a group of professions where the female sex dominates, and people who show mobbing behavior and the victims are female nurses at high levels. From this point of view, being a female dominant profession group is closely related to mobbing. Nurse executives are usually the ones who show the real mobbing behavior in the profession. It can be said that personal traits such as personal insecurity, bad interpersonal communication skills, low self-esteem and being unqualified for the position play a role on abuse of the authority (Johnston et al. 2009).

As a result of an international study conducted in 2008, including the United States and 17 other countries, it is stated that according to the employees, employee safety is not prioritized in the working environment. Approximately $93 \%$ of the responders are nurses and they stated that mobbing, which is one of the types of workplace violence, is increasingly being seen among nurses (Johnston et al. 2009). 
Studies on workplace violence show that healthcare professionals are 16 times more exposed to mobbing and nurses are 3 times riskier in this group (Kingma 2001). Another study shows that female nurses are the primary victims of mobbing activities (Iglesias and Vallejo 2012). In a study conducted in UK, it is reported that approximately $95 \%$ of the nurses' face behaviors assessed within the scope of mobbing in the workplace (Kingma 2001). According to other international studies; in the study conducted by Fute et al. (2015), it is stated that $90 \%$ of the nurses are exposed to verbal assault/abuse. Likewise, in other studies, it is seen that mobbing perception of the nurses is formed especially with the verbal behaviors of violence (Efe and Ayaz 2010, Yildirım 2009, Ovayolu et al. 2014, Pai and Lee 2011, WBI 2014, Naime 2012). In the study on workplace violence which was conducted on 1377 nurses, Hader (2008) determined that the most frequent types of violence according to the nurses' perspective are intimidation, sudden burst of anger, threatening and disruptive behaviors which are categorized under the title of mobbing. Y1ldirım (2009) determined that nurses face most frequently personal and occupational bullying. Quine (1999) identified mostly reported mobbing behaviors as changing rules unfairly to raise difficulties, hiding necessary information, creating pressure which blocks production, ignoring, exclusion and isolating from society with hostile attitude. Efe and Ayaz (2010), who examine nurses' state of exposure to mobbing and its causes, show that while about $10 \%$ of the nurses are exposed to mobbing according to the result of the applied mobbing scale, the results obtained according to nurses' own declarations are $33 \%$. Öztürk et al. (2007) reported that $39 \%$ of the nurses were mobbing victims, yet $42 \%$ of the victim groups were found to be real mobbing victims. When the studies are examined, trying to determine and measure the mobbing victimization directly by ignoring the pre-existing negative attitudes of the individuals related to exposure to mobbing explains shady height of the results. These differences in results show us the vagueness as to what kind of behaviors nurses perceive as mobbing. Each negative behavior faced in the work environment is not mobbing. In order to raise awareness for nurses about this subject, it is an important issue needed to be practiced with them to determine which behaviors and processes should be assessed as mobbing.

When factors affecting mobbing in the workplace are taken into consideration, it is shown that working in psychiatry units is a factor (Richter 2006, Johnston et al. 2009, Acar et al. 2014, Sinat 2007). Although there have been a lot of studies on mobbing, a study conducted with psychiatric nurses who are under more risk of stressful working environment that triggers mobbing has not been encountered. That studies focus generally on rates of mobbing on nurses but it is not clear which behaviors/situations are perceived as mobbing by the nurses and that each negative behavior is perceived as mobbing in the institutions, this study was planned. Research questions determined within this scope are;

-What is the mobbing perception of the nurses working in psychiatry clinics?

-What are the affecting factors of the mobbing perception of the nurses working in psychiatry clinics?

\section{2 | METHODS}

Type of Research

The research was conducted as descriptive and correlational research to determine the mobbing perceptions of nurses working in psychiatry clinics and the related factors affecting perceptions.

Population and Sample of the Research

Medical faculty hospitals, private mental health hospitals in Istanbul which has the most power to represent Turkey, ministerial psychiatric hospitals in Istanbul and 350 nurses working in psychiatry clinics of training and research hospitals formed the population of the research.

The sample of the study consisted of nurses working in psychiatry clinics $(n=296)$ in 6 hospitals that allowed the research to be carried out. The sample size (survey return rate is 69\%) was formed with 204 people (Table 1). Nurses who worked in the same psychiatry clinic at least for 4 months before the sample selection and accepted to participate in the study were included in the research.

Data Collection Tools

22 questions including participants' individual, occupational traits and states related to mobbing were 
asked with 'Information Form' developed by the researcher (Atasoy 2010, Yavuz 2007). Information form includes 3 sub-sections in total. In terms of individual traits; questions as to demographic data such as age, gender, marital status, having children, in terms of occupational traits; questions about educational status, years of experience and working times, satisfaction, department worked, duty, working times, number of patients being cared, type of employment, income status, union membership, in terms of mobbing states; questions about exposure to mobbing, institutional features about mobbing, consultancy and legal compliance are taken place.

'Workplace Mobbing Scale', which is used in the study to determine nurses' mobbing perception, is a 28 point scale including mobbing beheviors in workplace and it is prepared in rating (4 likert type) question form to determine the mobbing rate and behavior types (Tinaz 2006). The scale consists of 4 factors and these are work-related behaviors, disreputable behaviors, excluding behaviors, and verbal, written and visual attacks. Chi-Square was used in the analysis of data, mean and frequency tests were utilized. Also, explanatory factor analysis was carried out to classify the articles, which are interrelated and measure the same dimension, in the questionnaire. Test results were evaluated according to $5 \%$ $(p<.05)$ significance level. Cronbach Alpha reliability coefficient of the scale was determined as .93. Cronbach Alpha values were determined according to the factors as; .86 for the first dimension, .82 for the second dimension, .80 for the third dimension and .79 for the fourth dimension. In order study to be conducted, required ethics committee approval and verbal, written consent of the nurses were obtained. The cronbach alpha valua of scale .92 in this study that indicates 'workplace mobbing scale' is valid and reliable instrument in Turkish population.

\section{3 | RESULTS}

Findings belonging to the individual traits of 204 nurses who participated in the research are seen in table 2.

$74 \%$ of the participating nurses are women, $40 \%$ are between the ages $31-40,31 \%$ are between the ages
$21-30,58 \%$ are married and $54 \%$ have child.

When findings related to the occupational features of the nurses are examined, $58 \%$ of them are satisfied with the institution they work with and 54\% are satisfied with the type of employment. 34\% are undergraduates and $35 \%$ are associate degree graduates. $86 \%$ are service nurses and $43 \%$ are working day/night shifts.

When traits of the nurses in terms of mobbing are examined, it is seen that $53 \%$ of them were exposed to mobbing during their professional life, $80 \%$ of them had no information about the legal dimension of mobbing and its counseling and 59\% of them did not receive in-service training related to mobbing. The responses of the nurses to the articles of 'Workplace Mobbing Scale' are shown in table 3.

As it is seen in table 3, while behaviors evaluated within 'work-related behaviors' sub-dimension of the Workplace Mobbing Scale are the most frequently encountered mobbing behaviors, behaviors belonging to sub-dimension of 'verbal, written and visual mistreatments' and 'excluding behaviors' are least encountered mobbing behaviors.

A significant difference was determined between satisfaction from the institution, education status, type of employment and satisfaction status, period of occupational experience, exposure to mobbing and knowing the processes of consultancy in case of mobbing from independent variables and subdimensions of Workplace Mobbing Scale. It was determined that nurses who are partially satisfied with the institution and type of employment and who are not satisfied with their work and constantly work at night, nurses with high level of education and professional experience between 16-20 years encounter more mobbing behaviors. It was seen that nurses who stated that they had faced with mobbing are mostly exposed to work-related behaviors from sub-dimensions of Workplace Mobbing Scale. It was found that people who know from which institution or whom they can receive consultancy or the legal dimension of the situation in case of mobbing are exposed to more excluding behaviors. 


\section{4 | DISCUSSION}

Although there are many studies in the literature that measure the frequency of nurses' exposure to mobbing, it is not clear with how much frequency a behavior is mobbing, and what the mobbing perceptions of the people are. The majority of negative situations in workplaces are attributed to mobbing, which is the starting point of this study. Psychiatry clinics are units that are more stressed in terms of working conditions and that working conditions are heavier due to nurse inadequacy. The aim of this study, which is based on the hypothesis that psychiatric nurses are at more risk for the factors leading to the formation of mobbing, is to determine the behaviors and related factors of mobbing perceptions of nurses in general, specifically of psychiatric nurses. In this context, most of the nurses who participated in the research are women, married and have children. When the age ranges are examined, the group with the highest frequency is $31-40$ years old. $97 \%$ of the sample is consisted of nurses working in public institutions and nurses under the age of 40 represent $71 \%$ of the sample. It was determined in this study that nurses did not differ according to individual features of their mobbing perceptions. As the female gender is more common, most of them are married and have children, it can be considered that the study reflect the profile of public hospitals employees. In this study, there is not any difference between the individual features of nurses in terms of gender, marital status, having children, age and behaviors perceived as mobbing. Similarly, Köksal (2011) could not find a significant relationship between age and exposure to mobbing. In the study of Yavuz (2007) themed as 'factors affecting mobbing perceptions in employees', it was seen that as the age increases, the mobbing perception increases. Efe and Ayaz (2010) determined that nurses under the age of 25 and Akyil et al. (2012) determined that young nurses are exposed to more mobbing behaviors. In their studies, Geçici and Sağkal (2011) found that female nurses are more likely to encounter mobbing behaviors. Tinaz (2006) and Tanoğlu (2006) interpreted this situation as mobbing behaviors are encountered more frequently in the health sector where women work more intensively and women prefer to show passive aggressive behavior towards their same-gender. Yavuz (2007) found that employees' mobbing perceptions did not differ according to gender. While psychiatry clinics are an area where male nurses are employed more, female gender has a $74 \%$ rate in this study. In order to explain the relation between gender and behaviors perceived as mobbing, studies in which male nurse sample is more, similar to age independent variable, are needed.

When findings related to occupational features of nurses are examined, as the level of education gets higher, the level of exposure to mobbing behaviors evaluated within the sub-dimension of work-related behaviors is at higher level. Significant conclusion was drawn in terms of behaviors that are disreputable for nurses with postgraduate education level. In the study of Yavuz (2007), it was found out that the employees' mobbing perceptions increase with the increase of education level. In their studies, Köksal (2011), Bardakçı and Günüşen (2016) encountered parallel findings with this study. This situation can be evaluated as indicating the competition within the institutions and it can be considered that competition comes off as a reaction against mobbing and employees' promotion. Contrary to mentioned studies, Akyil et al. (2012) and Efe and Ayaz (2010) determined that younger and inexperienced nurses with lower education levels are exposed to more mobbing behaviors. They associated this situation to the fact that education in vocational schools is not sufficient for communication skills and mobbing/conflict management. Nurses, who are dissatisfied with their work are more likely to encounter mobbing behaviors. In other words, as satisfaction decreased, nurses were found to be more likely to encounter four different dimensions of mobbing behaviors. When nurses' type of employment are examined, those who are 'always on night' shift and are not satisfied with their work reported thay they are exposed to significantly more mobbing behaviors than all other employees. Similarly, Akyil et al. (2012) and Lin and Liu (2005) reported that the level of mobbing perceptions of nurses working at night were higher. In the study of Dilman (2007) it was stated that the nurses' level of satisfaction from the institution they work in and type of employment is high and that there is not any significant 
relation between type of employment and exposure to mobbing behavior. This situation was explained as administration of nursing services is effective and it cares about personnel satisfaction. According to our country's standards, large number of nurses are involved in team work in hospitals during the day shift, fewer staff are employed in night shifts, and as a matter of fact only single personnel is employed in most units. Chronic nurse inadequacy increases the level of stress of the employees and reduces the level of interpersonal interaction. This situation facilitates the emergence of conflicts. The relationship between inappropriate working conditions and the occurrence of mobbing behaviors was explained by Tong et al. (2017). Various factors such as the level and type of communication, being not able to carry workload, sleeplessness and fatigue, biological unbalance can cause nurses working 'always on night shift' encounter more disreputable behaviors and verbal, written and visual mistreatments. The results of the research show that there is a significant difference between the level of satisfaction from the institution and type of employment and mobbing behavior (Tong et al. 2017). Employees are more likely to face mobbing behaviors as their level of satisfaction decreases. More detailed studies to be done about this subject should be used to assess the working conditions of the nurses. Nurses with 16-20 years of professional experience are more exposed to disreputable and excluding behaviors. Fişkın (2011) found that the rate of mobbing encountered by the people who have 5-9 years of professional experience is $80 \%$. According to the research result of Bahçe (2007); mobbing behaviors are mostly encountered by employees between 11 and 15 years of professional experience. Akyil et al. (2012) reported that nurses with less professional experience have higher rates of mobbing. When looking at the results of different studies, the relationship between mobbing behaviors and years of professional experience has different results. It is thought that more research in this field with homogeneous and large sample groups are needed to be done.

In the research, nurses (n:109, 53\%), who stated that they are exposed to mobbing throughout their career, encounter more work-related behaviors. Most of the nurses who stated that they are exposed to mobbing behaviors reported that they did not encounter subdimension behaviors as disreputable, excluding, verbal, written and visual mistreatments. In the study of Dilman (2007), it was seen that $70 \%$ of the nurses are exposed to mobbing behavior, in the study of Fişkın (2011), the result was $65 \%$ and in the study of Bardakçı and Günüşen (2016), it was 29\%. In terms of mobbing experience rate, research results differ from one study to another. Studies show that nurses encounter high level of mobbing behaviors and although the subject is not new, it is still a serious problem in their profession. On the other hand, when literature knowledge is taken into consideration, systematical exposure to behaviors is needed in order for people to be regarded as mobbing victims. Employees should be informed that exposure to any of the behaviors assessed under the mobbing behavior should not be considered as mobbing. It was found that people who know from which institution or whom they can receive consultancy or the legal dimension of the situation in case of mobbing are exposed to more excluding behaviors. In the study of Arisoy (2011), it was stated that the situation of $70 \%$ of the nurses not knowing what their legal rights and obligations are affects their exposure to mobbing. Aksakal et al. (2015) noted that nurses with mobbing experience are less likely to adopt concrete actions such as receive counseling, resort to the jurisdiction, or ask help from professional associations. Akyil et al. (2012) found that nurses' awareness of mobbing is increasing, that they will be able to make oral and written complaints in response to future mobbing behaviors and will take an active role in following this process. On the other hand Aksakal et al. (2015), Bardakçı and Günüşen (2016) indicate that nurses prefer to remain unresponsive in case of mobbing actions and they share their experiences with family and close friends only. An employee who is aware of what his/her legal rights and obligations are, may be able to identify the mobbing behavior, have the ability to produce an appropriate solution to the situation, and differ from other employees by expressing the situation. This may cause the person to appear as standing out against senior management and administration, that is why his/her colleagues may be uncomfortable to be with him/her and avoid being called together. 
Nurses who reported that they had encountered mobbing behaviors at least once in their professional life stated that the behaviors mostly encountered by them are 'every work done by me is observed in details, works below my professional skills or damage my self-esteem are required from me, irrational duties and aims which are impossible to complete are set, I am not recognized in work-related subjects or I am interrupted when I speak, my decisions related to work are questioned and people show negative gestures or glances towards me'. When mostly encountered mobbing behaviors by the nurses are evaluated within the typology of Leymann, they belong to the groups of "showing yourself and blocking communication' and 'aggression towards person's quality of life and professional status'. In the study of Dilman (2007), behavior patterns with highest score are determined as 'always being interrupted, behaving as if I did not exist in the environment, being ignored, indirectly control of me and the works done by me'. The most common behaviors in Dilman (2007)'s study are within the work-related behaviors from sub-dimensions of Workplace Mobbing Scale. Üye (2009) stated that mobbing behaviors, which nurses are exposed to with the highest rate, are within 'disreputable and excluding behaviors' sub-dimension of Workplace Mobbing Scale. Fışkın (2011) determined that $65 \%$ of the nurses encountered similar sub-dimension behaviors with this study in the scope of mobbing behaviors. Sa and Fleming (2016) determined the most common mobbing behaviors for the nurses as 'being charged with works that are impossible to finish, restricting the area of responsibility and request of works below professional skills'. As it is seen, nurses mostly encounter behaviors within the sub-dimension of work-related and disreputable behaviors.

\section{5 | CONCLUSIONS}

Independent variables can be predicted more clearly by wider sampled studies with nurses working in psychiatry hospitals at private sector and other cities. As the satisfaction from the institution and the type of employment decreases within the scope of the occupational features of the nurses, the percentage of the nurses encountering all the sub-dimension behaviors of the mobbing increases. Nursing services administrations in hospitals should effectively organize the type of employment and specify strategies that will increase nurses' level of satisfaction from the institutions. Nurses with postgraduate education are more likely to encounter disreputable behaviors. A significant relation was detected between all sub-dimensions of Workplace Mobbing Scale and exposure to mobbing during career. It was found that people who know from which institution or whom they can receive consultancy or the legal dimension of the situation in case of mobbing are exposed to more excluding behaviors. Nurses should be informed about the mobbing with in-service training programs related to mobbing planned at regular intervals in institutions, updated information about the legal dimension related to mobbing should be given to nurses, and information about the centers where counseling can be received should be given. According to the nurses' responses to Workplace Mobbing Scale, the mostly encountered behaviors within work-related and excluding behaviors are; 'every work done by me is observed in details, works below my professional skills or damage my self-esteem are required from me, irrational duties and aims which are impossible to complete are set, I am not recognized in work-related subjects or I am interrupted when I speak, my decisions related to work are questioned and I am the one who is always seen as the responsible of every problem'. The results of the study on mobbing should be shared with the nursing services administration and nurses in order to expand awareness.

\section{REFERENCES}

1. Acar, P, Kiyak, M, \& Sine, B. (2014). The relationship between organizational culture and mobbing: an application on construction companies. Journal of Workplace Behavioral Health, 29(4), 281-298.

2. Adams A. (1992). Bullying at work: how to confront and overcome 1t. London: Virago.

3. Aksakal, F.N.B., Karaşahin, E.F., Dikmen,A.U., Avci, E., \& Özkan, S. (2015). Workplace physical violence, verbal violence, and mobbing experienced by nurses at a university hospital. Turkish Journal Of Medical Sciences, 45(6), 1360-1368. 
4. Akyil, R.Ç., Tan, M., Saritaş, S., \& Altuntaş, S. (2012). Levels of mobbing perception among nurses in Eastern Turkey. International Nursing Review, 59(3), 402-408.

5. Arısoy, A. (2011). Mobbingi ortaya çıkaran faktörler: Isparta- Antalya- Burdur'da sağlı sektöründe hemşireler üzerine çalışma [The Factors occur mobbing: The study on the nurses working at the health sector in Antalya-Burdur-Isparta] (master's thesis). Süleyman Demirel University Institute of Social Sciences, Isparta, Turkey.

6. Atasoy, I. (2010). Sağlik sektöründe mobbing: Sakarya ilinde kamu ve özel hastanelerde çalışan ebe ve hemşireler üzerine bir araştırma [Mobbing in health sector a survey on nurses and midwifes working at the public and private hospitals in Sakarya] (master's thesis). Sakarya University Institute of Social Sciences, Sakarya, Turkey.

7. Bahçe, Ç. (2007). Mobbing oluşumunda örgüt kültürünün rolü: örnek bir uygulama [The role of organization culture in formation of mobbing: Implement a example] (master's thesis). Gazi University Institute of Social Sciences, Ankara, Turkey.

8. Bardakçı, E., \& Günüşen, N.P. (2016). Influence of workplace bullying on turkish nurses' psychological distress and nurses' reactions to bullying. Journal of Transcultural Nursing, 27(2), 166-171.

9. Bradbury, J., \& Hutchinson, M. (2015). Workplace bullying: modelling construct validity in an Australian public sector workforce. Journal of Empirical Studies, 2(1), 1-16.

10. Cleary, M, Hunt, G. E, \& Horsfall, J. (2010). Identifying and addressing bullying in nursing. Issues in Mental Health Nursing, 31(5), 331-335.

11. Davenport, N.Z., Schwartz, R.D., \& Elliott, G.P. (2003). Mobbing, emotional abuse in the American workplace. [Translated by Osman CemÖnertoy]. Istanbul, Turkey: Sistem Yayıncılık.

12. Dilman, T. (2007). Özel hastanelerde çalışan hemşirelerin duygusal tacize maruz kalma durumlarının belirlenmesi [Defining the situation of mobbing experience among the nurses working in private hospitals] (master's thesis). Marmara University Institute of Health Sciences, Istanbul, Turkey.

13. Efe, S.Y, \& Ayaz, S. (2010). Mobbing against nurses in the workplace in Turkey. International
Nursing Review, 57(3), 328-334.

14. Elena Losa Iglesias, M., \& Becerro de Bengoa Vallejo, R. (2012). Prevalence of bullying at work and its association with self-esteem scores in a Spanish nurse sample. Contemporary Nurse, 42(1), 2-10.

15. Fışkın, G. (2011). Mobbing davranışı ve ana çocuk sağlığı merkezlerindeki sağlık çalışanlarına yönelik bir araştırma [A study on mobbing behaviour, aimed at the medical staff employed in the centers for maternal and infant healthcare] (master's thesis). Istanbul University, Institute of Health Sciences, Istanbul, Turkey.

16. Fute, M, Mengesha, Z.B, Wakgari, N, \& Tessema, G.A. (2015). High prevalence of workplace violence among nurses working at public health facilities in Southern Ethiopia. BMC Nursing, 14(1), 1 .

17. Geçici, B.N, \& Sağkal, T. (2011). Ödemiş’te çalışan hemşirelerin mobbinge maruz kalma durumlarının incelenmesi [A Survey about the State Of Nurses Who Experienced Mobbing In Ödemis]. Maltepe University Journal of Nursing, Science and Art, 4-1, 53-62.

18. Giorgi, G, Leon-Perez, J.M, \& Arenas, A. (2015). Are bullying behaviors tolerated in some cultures? Evidence for a curvilinear relationship between workplace bullying and job satisfaction among Italian workers. Journal of Business Ethics, 131(1), 227 237.

19. Hader, R. (2008). Workplace violence survey 2008: Unsettling findings. Nursing Management, 39(7), 13-19.

20. Hamilton, J.M. (2007). Creating healthy workplaces: what every nurse can do. The Pennsylvania Nurse, 62(2), 25-27.

21. ILO, I, \& WHO, P. (2002). Framework guidelines for addressing workplace violence in the health sector. Joint program on workplace violence in the health sector. International Labour Office, Geneva.

22. Johnston, M, Phanhtharath, P, \& Jackson, B. S. (2009). The bullying aspect of workplace violence in nursing. Critical Care Nursing Quarterly, 32(4), 287295.

23. Karsavuran, S. (2014). Sağllk sektöründe mobbing: hastane yöneticileri üzerinde bir uygulama 


\section{MEERP LTD}

[Mobbing in Healthcare: An Application to Hospital Managers]. Mustafa Kemal University Journal of Social Sciences Institute, 11(26).

24. Khoshknab, M.F, Oskouie, F, Najafi, F, Ghazanfari, N, Tamizi, Z, \& Ahmadvand, H. (2015). Psychological violence in the healthcare settings in Iran: A cross-sectionalstudy. Nursing and Midwifery
Studies, 4(1).

How to cite this article: D.K.D., D.V.D. Perception of Nurses' Work in Psychiatric Clinic. Clinical Medicine Insight. 2020;27-35. https://doi.org/ $10.52845 / \mathrm{CMI} / 2020 \mathrm{v} 1 \mathrm{ila} 5$ 